\section{Comment on Chiesi et al. (2011): "Use of BIOME-BGC to simulate Mediterranean forest carbon stocks"}

\author{
Eastaugh CS
}

The mechanistic forest growth model BIOME-BGC utilizes a "spin-up" procedure to estimate site parameters for forests in a steady-state condition, as they may have been expected to be prior to anthropogenic influence. Forests in this condition have no net growth, as living biomass accumulation is balanced by mortality. To simulate current ecosystems it is necessary to reset the model to reflect a forest of the correct development stage. The alternative approach of simply post-adjusting the estimates of net primary production is fundamentally flawed, and should not be pursued.

Keywords: Increment, Biogeochemical model, Spin-up, Steady-state

Recently in these pages Chiesi et al. (2011) described the application of the BIOME-BGC mechanistic forest growth model to Mediterranean forests in Tuscany, Italy. Their primary conclusions were that the model overestimates standing volumes, but that an empirical adjustment of net primary production (NPP) and a recalibration of the whole annual plant mortality fraction (WPMF) is sufficient to align simulations with observations. This approach negates the logic of the model and their artificial reproduction of observed volume and increment neither advances understanding of forested ecosystems nor provides a useful diagnostic or predictive tool.

The BIOME-BGC model relies on a "spinup" simulation (commonly spanning several millenia) to estimate site parameters in what Chiesi and colleagues call a "quasi-equilibrium" condition. More precisely, this should be labeled a "steady state" condition, where over some time period inputs to the system are balanced by outputs. This can be conceptually viewed as an "old growth" forest ecosystem, as it may have existed prior to anthropogenic disturbance. Crucially, in this steady state there is no net stand growth, increases in the living biomass pools are balanced by mortality. Unsurprisingly, the simulated standing volume in this state is generally considerably higher than that observed in today's European forests (Pietsch \& Hasenauer 2006). To calibrate the model, Chiesi and colleagues adjust the
WPMF parameter until simulated standing volumes match observations.

Among many other things, BIOME-BGC tracks the mass of carbon in the aboveground living woody biomass pool. With appropriate biomass expansion factors and allometric relationships, this can be used to estimate standing timber volume. Other pools and fluxes in the system are kept in relative balance with each other, and conform with physiological realities. Changes in standing volume over time represent both increment and mortality, which in a steady state should approach zero.

Chiesi and colleagues calculate the ratio between observed and simulated standing volume, and use this to "correct" model NPP outputs. The presumed stand increment is then derived as a function of NPP (instead of directly from the changes in stem carbon), and Chiesi and colleagues show an improved estimate with their new WPMF parameterization. NPP is however not the same thing as growth, particularly in old forests. The simulated "CAI" that is presented in Chiesi and colleagues' Fig. 5 is not a true measure of increment, but is a direct function of modelled stand mortality. This is supported by a close comparison of Fig. 5 with Tab. 2, showing tional to the applied increase in WPMF from the 0.005 base.

The core of the problem is that the model is simulating an old-growth, steady state forest stand, while the observations are from that the change in modelled "CAI" is propor- $\square$ Institute of Silviculture, University of Natural Resources and Life Sciences (BOKU), Vienna (Austria).

(a) Chris S. Eastaugh

(chris.eastaugh@boku.ac.at)

Received: Jul 12, 2011 - Accepted: Jul 27, 2011

Citation: Eastaugh CS, 2011. Comment on Chiesi et al. (2011): "Use of BIOME-BGC to simulate Mediterranean forest carbon stocks". iForest 4: 248 [online 2011-11-03] URL: http://www.sisef.it/iforest/show.php? id $=593$

younger, actively growing stands. A successful means of dealing with this was pioneered by Pietsch \& Hasenauer (2002), where the model is stopped at the end of the spin-up and one or more forest "clear-cut" harvesting operations are simulated and the model restarted. The timing of the final clear-cut and replanting is chosen so that the simulated stand age is the same as the observed stand. Biomass removals due to thinning or other disturbances can be similarly included. This technique retains physiological credibility, and has been shown to be able to produce results compatible with National Forest Inventories (Eastaugh et al. 2011). The methods of Chiesi and colleagues may produce model outputs that align with observed stand increment, but their model will have no explanatory or predictive power because they do not simulate an actively growing stand.

\section{References}

Chiesi M, Chirici G, Barbati A, Salvati R, Maselli F (2011). Use of BIOME_BGC to simulate Mediterranean forest carbon stocks. iForest 4: 121-127. - doi: 10.3832/ifor0561-004

Eastaugh CS, Pötzelsberger E, Hasenauer $\mathrm{H}$ (2011). Assessing the impacts of climate change and nitrogen deposition on Norway spruce (Picea abies L. Karst) growth in Austria with BIOME-BGC. Tree Physiology 31(3):262-274. - doi: 10.1093/treephys/tpr033

Pietsch SA, Hasenauer H (2002). Using mechanistic modelling within forest ecosystem restoration. Forest Ecology and Management 159: 111131. - doi: 10.1016/S0378-1127(01)00714-9

Pietsch SA, Hasenauer H (2006). Evaluating the self-initialization procedure for large-scale ecosystem models. Global Change Biology 12 (9): 1658-1669. - doi: 10.1111/j.1365-2486.2006. 01211.x 